\title{
Resultative constructions in heritage Ambon Malay in the Netherlands*
}

\author{
Francesca R. Moro \\ Radboud University Nijmegen
}

Domains where languages have two or more competing syntactic constructions expressing the same meaning may be problematic for bilingual heritage speakers. One such variable domain is the resultative constructions in heritage Ambon Malay, a variety spoken in the Netherlands by Dutch-Ambon Malay bilinguals. In Ambon Malay, resultatives are expressed mostly by means of verb serialization (SVC), although resultative prepositional phrases (PP) and adjectival phrases (AP) also occur. In Dutch, resultative constructions usually involve verb particles, PPs and APs. This overlap of structures poses the conditions for transfer effects between the two languages. The frequency distribution of SVCs, PPs and APs is investigated in semi-spontaneous speech from heritage speakers of Ambon Malay and compared to that of baseline speakers. Heritage speakers show an increase in the frequency of constructions shared by both languages (PPs and APs), while they underuse the constructions attested only in the heritage language (SVC).

Keywords: Heritage language, bilingualism, Ambon Malay, resultative constructions, serial verb constructions

\section{Introduction}

This paper investigates changes in resultative constructions between two language varieties, namely baseline ${ }^{1}$ Ambon Malay (spoken in Indonesia) and heritage Ambon Malay, spoken by Dutch-Ambon Malay bilinguals in the Netherlands. Ambon Malay is spoken as a heritage language by the descendants of the 12.500 Ambon Malay speakers who arrived in the Netherlands in the early 1950s, after the decolonization of Indonesia ${ }^{2}$ (Veenman 1994). In the heritage variety of Ambon Malay, a number of changes have occurred, which are due to the heritage speakers' path of language acquisition and due to the intense contact with Dutch (Tahitu 1989; Huwaë 1992; Lekawael 2011). 
Resultatives are an interesting area for the study of language contact phenomena because we know from previous research that the domains where languages have two (or more) competing syntactic constructions expressing the same meaning are problematic for bilingual (heritage) speakers. In fact, when the heritage language has an alternation between two constructions, heritage speakers will tend to overgeneralize the construction also present in the dominant language (Backus 2004; Silva-Corvalán 2008; cf. also 'The Alternation Hypothesis' in Jansen, Lalleman \& Muysken 1981). This has been shown for possessive constructions in heritage Moroccan Arabic and heritage Ambon Malay in the Netherlands (Muysken 2005: 15; Boumans 2006) and for subordinate clauses in heritage Turkish in the Netherlands (Onar Valk \& Backus 2013). In many languages, including Ambon Malay and Dutch, the domain of resultatives allows variable syntactic encoding (Kaufmann \& Wunderlich 1998; Talmy 2000; Croft, Barðdal, Hollmann, Sotirova \& Taoka 2010). In Ambon Malay, resultatives are expressed mostly by means of serial verb constructions (SVC, example 1$)^{3}$ and verb coordination, although resultative prepositional phrases (PP, example 2 ) and adjectival phrases ${ }^{4}$ (AP, example 3$)^{5}$ also occur (see Tjia 1997).

Resultative SVC

Ambon Malay

(1) Perempuan [robe kain jadi dua]

girl tear cloth become two

'A girl tore a piece of cloth into two (lit.: tore a piece of cloth became two).'

Resultative PP

Ambon Malay

(2) Nona robe akang [par dua]

girl tear 3sG.N to two

'A girl tore it (a piece of cloth) into two.'

Resultative AP

Ambon Malay

(3) Oe setang sapasu lemparkaca [pica] tu

EXCL. ghost who PERF pelt glass broken ILOC

'Hey, who the hell pelted the glass (until it got) broken?'

In Dutch, resultative constructions usually involve verb particles, PPs (example 4) and APs (example 5) (Elektronische ANS 20-9-4; Kaufmann \& Wunderlich 1998; van Kemenade \& Los 2003).

Resultative PP

Dutch

(4) Een vrouw scheurt een doek [in tweeёn]

a womantears a cloth in two

'A woman tears a piece of cloth into two.' 
Resultative AP

Dutch

(5) Een vrouw slat een vaas [kapot]

a woman hits a vase broken

'A woman hits a pot (until it got) broken.'

The fact that Ambon Malay and Dutch display two different but partially overlapping patterns and the variation found in this domain are likely to pose a challenge to heritage speakers. Following the findings of other studies (Backus 2004; Boumans 2006; Silva-Corvalán 2008), I hypothesize that the (partial) parallelism between Ambon Malay and Dutch will create the condition for changes in the frequency distribution of resultative constructions in heritage Ambon Malay. Heritage speakers will tend to overgeneralize the constructions shared by both languages (PPs and APs), while they will underuse the constructions attested only in the heritage language (verb serialization and verb coordination).

These predictions are corroborated by a separate study on verb serialization in a language contact situation involving a similar language pair. Tetun Dili is an Austronesian serializing language in contact with a non-serializing European language, Portuguese. Hajek (2006) explains that the long-term contact with Portuguese has significantly reduced the frequency and range of SVC types in Tetun Dili, which have been replaced by lexical verbs (loans from Portuguese) and prepositions. This study demonstrates that the loss of SVCs can be contactinduced (see Aikhenvald 2006:53).

The prediction that heritage Ambon Malay will also display a loss of SVCs due to the long-term contact with Dutch is borne out by the data, which show a clear shift in the frequency distribution of resultative constructions in heritage speakers.

The paper is organized as follows. Section 2 outlines the theoretical background of this study and Section 3 clarifies the methodology used for this study. In Section 4, I summarize the results, which are then further discussed in Section 5. Section 6 concludes the paper.

\section{Theoretical background}

In this paper, I adopt a usage-based constructional approach to resultatives (Goldberg 1995; Boas 2003) and to language acquisition (Tomasello 2000, 2009; Ellis 2006). In the constructional approach, the basic unit is the construction, i.e. a conventionalized form-meaning correspondence. This approach considers resultatives as independently existing meaningful constructions, which are associated with a specific meaning and a specific syntactic configuration, independently of the words which instantiate them (Goldberg 1995; Boas 2003). The specific 
meaning of the resultative construction is ' $\mathrm{X}$ CAUSES Y TO BECOME Z', which is mapped onto the syntactic structure NP V NP R(esult) P. In the usage-based approach, syntactic and semantic restrictions on resultatives are explained in terms of language usage rather than in terms of parameter settings or principles. Boas (2003:278) specifies that resultatives are licensed "by event-frame semantic information that determines, (a) whether a given verb may occur with resultatives, and (b) what type of resultative a given verb may occur with".

In the usage-based constructional approach, language acquisition is seen as a process in which the child learns constructions in a bottom-up manner through use (Tomasello 2009). The acquisition of linguistic knowledge depends on inputrelated factors, such as frequency, acoustic saliency and semantic transparency, which facilitate the establishment and strengthening of form-meaning correspondences (O’Grady, Kwak, Lee \& Lee 2011). According to Ellis (2006: 1), “language acquisition is contingency learning, that is the gathering of information about the relative frequencies of form-function mappings". Tomasello (2000:72) points out that both token and type frequency are necessary in language acquisition: Token frequency "tends to entrench an expression - enabling the user to access and fluently use the expression as a whole", while type frequency "determines the creative possibilities, or productivity, of the construction".

Frequency and entrenchment also play a role in contact-induced language change. As pointed out by Backus (2004:179), "one way of representing the diachronic process of language change is as shifts in 'entrenchment'”. Several studies have shown that in bilingual individuals, the frequency of a construction in one language can influence the degree of entrenchment of the corresponding construction in the other language (Boumans 2006; Onar Valk \& Backus 2013). In fact, bilinguals tend to prefer constructions common to both languages; and when L2 has optionality, the construction shared by the L1 is preferred. Muysken (2013:721) observes that "perhaps the best candidate for L1-oriented syntactic change is the relative increase in use in partial maintenance settings, under influence of another language, of a construction which is already present in a language".

This type of syntactic change, namely a change involving only the frequency distribution of already existing constructions, has been referred to as indirect transfer' by Silva-Corvalán (1994:4) and as 'frequential copying' by Johanson (2002:292). For Backus (2004: 180), a change that is not altering but only restructuring the frequencies of constructions in a system is a 'system-preserving change'. 


\section{The present study}

In this paper, I investigate the frequency distribution of competing resultative constructions, namely verb serialization, verb coordination, PPs and APs in semispontaneous speech from heritage speakers of Ambon Malay in the Netherlands. I compared resultative constructions in heritage Ambon Malay to those of baseline Ambon Malay in order to detect signs of structural divergence between the two varieties, and to those of Dutch in order to find out signs of structural convergence between the heritage language and the dominant language.

I expect different behaviours between the constructions shared with Dutch (PP and APs) and those that are not shared (verb serialization and coordination), such that the shared constructions will show an increase in frequency and the non-shared constructions a decrease.

I will be concerned only with resultative constructions involving verbs for cutting, breaking and hitting because of the nature of the stimulus material. Interestingly, however, due to their semantic differences, these verbs are likely to trigger different types of resultative constructions. Verbs for cutting and breaking (hereafter $\mathrm{CB}$ ) entail a change of state in the entity affected, whereas verbs for hitting do not necessarily entail that the contact has any effect on the entity (Levin 1993: 150). In the Dutch dataset the CB verb scheuren 'tear' occurred almost always with a resultative PP (scheuren in tweeën 'tear into two') (80\%), while the verb slaan 'hit' occurred almost always with a resultative AP (slaan een vaas kapot, lit.: 'hit a vase broken') (80\%). CB verbs usually select a resultative PP because PPs simply specify the change of state that is already encoded by the base verb without introducing independent information (Kaufmann \& Wunderlich 1998: 14). In contrast, verbs for hitting tend to select a resultative AP because APs add independent information, namely a new sub-event (become X) which is not implied by the base verb (Kaufmann \& Wunderlich 1998:41).

\subsection{Participants and methodology}

Three groups of speakers participated in the study: (i) A group of heritage speakers of Ambon Malay in the Netherlands, (ii) a control group of baseline Ambon Malay speakers, and (iii) a control group of Dutch speakers. The heritage group consists of 33 heritage speakers of Ambon Malay who were born ${ }^{6}$ and raised in the Netherlands. These speakers are all bilinguals with Dutch as their dominant language. The first control group consists of 33 Ambon Malay speakers: 27 are homeland speakers and six are first generation speakers in the Netherlands. I will refer to them collectively as the 'baseline' control group, since I assume that these speakers represent the variety of Ambon Malay from which the heritage Ambon 
Malay variety in the Netherlands derives. The second control group consists of 10 adult Dutch speakers recorded in the Middelburg-Vlissingen area. ${ }^{7}$

The dataset consists of descriptions elicited by means of video clips selected from the fieldwork material designed by Bohnemeyer, Bowerman \& Brown (2001:90-95). The ten video clips showed resultative events of various kinds (e.g. cut fish into three pieces with knife; break a stick into two pieces; smash flowerpot with hammer).

A snapshot of two of the video clips used for the present study is given in Figure 1.
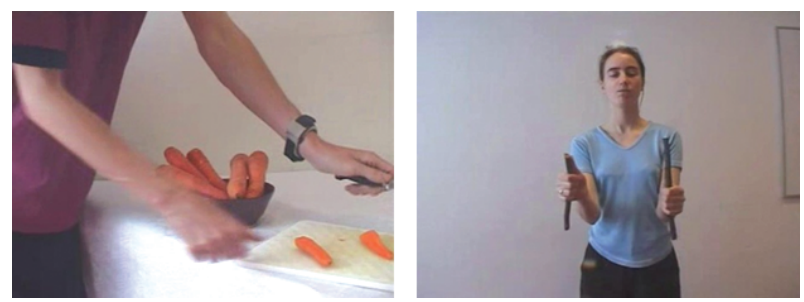

Figure 1. Examples of cut and break video clips used as elicitation stimuli

All 76 participants were asked to watch the videos, and to describe the event. The dataset contained 330 responses for the Ambon Malay heritage group (33 speakers x 10 clips); 330 responses for the Ambon Malay baseline group (33 speakers x 10 clips); 100 responses for the Dutch baseline group (10 speakers x 10 clips). Responses were coded along several dimensions, including type of resultative construction. Twenty-four responses were excluded because the speakers did not describe the target event.

\section{Results}

The set of constructions used by baseline speakers and heritage speakers is the same, but the frequency is different in the two groups. Before turning to the quantitative differences, I present an example of each construction in (6)-(10):

(6) Serial Verb Construction (SVC):

$\begin{array}{ccc}\mathrm{V}_{1} & \mathrm{~V}_{2} & \\ \text { Perempuan [robe kain jadi } & \text { dua] }\end{array}$

girl tear cloth become two

'A girl tore a piece of cloth into two (lit.: tore a piece of cloth became two).' 
(7) Coordination:

$$
\mathrm{V}_{1} \quad \mathrm{~V}_{2}
$$

[Dia potong ikan] terus [ikan ta-bage tiga]

3sg cut fish then fish ACL-divide three

'She cut the fish and then the fish is divided in three.'

(8) Prepositional Phrase (PP):

$$
\mathrm{V} \quad \mathrm{PP}
$$

Nona robe akang [par dua]

girl tear 3sG.N to two

'A girl tore it (a piece of cloth) into two'.

(9) Adjectival Phrase (AP):

$\begin{array}{lll} & \mathrm{V} & \mathrm{AP} \\ \text { Orang laki dengan hamer } & \text { pukulpot=nya } & {[\text { rusa }]}\end{array}$

person male with hammer hit vase $=$ DEF broken

'A man with a hammer smashed the vase into pieces (lit: hit the vase broken).'

Finally, as shown in (10), speakers have also the option of leaving out any further specification of the RESULT.

(10) Unspecified Result:

Satu orang potong wortel

one person cut carrot

'A person cut a carrot.'

I will first summarize the quantitative differences in Table 1, and then discuss them in more detail below.

Table 1. Mean frequency, standard deviation and significance level of the resultative constructions in two groups of Ambon Malay speakers, the baseline group and the heritage group.

\begin{tabular}{lllll}
\hline & Group & Mean in \% & Std. deviation & Sig. (2 tailed) \\
\hline SVC & baseline & 37.06 & .16033 & .000 \\
Coordination & heritage & 10.03 & .16584 & \\
& baseline & 20.42 & .19029 & .000 \\
PP & heritage & 5.91 & .12264 & \\
& baseline & 0.61 & .03482 & .000 \\
AP & heritage & 11.12 & .1284 & \\
& baseline & 0.30 & .01741 & .010 \\
Unspecif. Result & heritage & 4.24 & .08303 & \\
& baseline & 34.18 & .18369 & .000 \\
& heritage & 59.55 & .21675 & \\
\hline
\end{tabular}


SVCs were used considerably more frequently in the baseline group (37.06\%) than in the heritage group (10.03\%). In the baseline group, SVCs are the preferred strategy and every baseline speaker provided at least one response containing a SVC. In the heritage group, on the contrary, SVCs were used significantly less and occurred only in $1 / 3$ of the speakers (13 out of 33$)(t(64)=6.732, p=.000)$. A similar picture emerges with respect to (intransitive) coordination, which was used significantly more by baseline speakers (20.42\%) than by heritage speakers $(5.91 \%)$ $(t(64)=4.952, p=.000)$.

PPs and APs are more frequent in the heritage group than in the baseline group. In baseline Ambon Malay, resultative PPs account for $0.6 \%$ of all responses, and the only two instances attested were provided by the same speaker. In heritage Ambon Malay, the frequency distribution of PPs shows a significant increase $(11.12 \%)(t(64)=-4.541, p=.000)$, and more than half of heritage speakers (17 out of 33) provided at least one PP construction.

APs were also used significantly more often by heritage speakers $(4.24 \%)$ than by baseline speakers $(0.3 \%)(t(64)=-2.668, p=.010)$. In the baseline Ambon Malay dataset, APs occur with an extremely low frequency, while in the heritage dataset their frequency increases; ten heritage speakers used an AP at least once.

With respect to the percentage rate of PPs and APS, heritage Ambon Malay is clearly in the middle (11.12\% and 4.24\%) between baseline Ambon Malay (0.6 and $0.3 \%)$ and Dutch (17.9\% and $8.40 \%)$.

Finally, heritage speakers have a stronger preference for leaving out any further specification of the RESULT $(t(64)=-5.128, p=.000)$. This preference correlates negatively with speech rate $(r=-.449, p=.009)$, indicating that less fluent speakers (those speaking at slower rate) are less likely to overtly express the RESULT. ${ }^{8}$

In order to better visualize the divergence between baseline speakers and heritage speakers, I included a Neighbour Joining Tree (unrooted) in Figure 2. The Neighbour Joining algorithm (NJ) is an agglomerative clustering method originally designed for phylogenetic analysis (Saitou \& Nei 1987). ${ }^{9}$ As shown in Figure 2, the divergence between the two varieties of Ambon Malay is reflected in the shape of the unrooted NJ tree showing a split between baseline speakers (B) and heritage speakers $(\mathrm{H})$. Baseline speakers cluster in the bottom part of the tree, while the majority of heritage speakers is on the upper part.

Two observations can be made by looking at Figure 2. First, seven heritage speakers (whose names are enclosed in circles) cluster with baseline speakers in the bottom part of the tree. Second, there are three baseline speakers (B30, B32, B33) who cluster in the upper part of the tree together with heritage speakers. Not surprisingly, these are first generation speakers in the Netherlands. The lower frequency of SVCs in these three speakers could be either an effect of attrition or an effect of aging. ${ }^{10}$ 


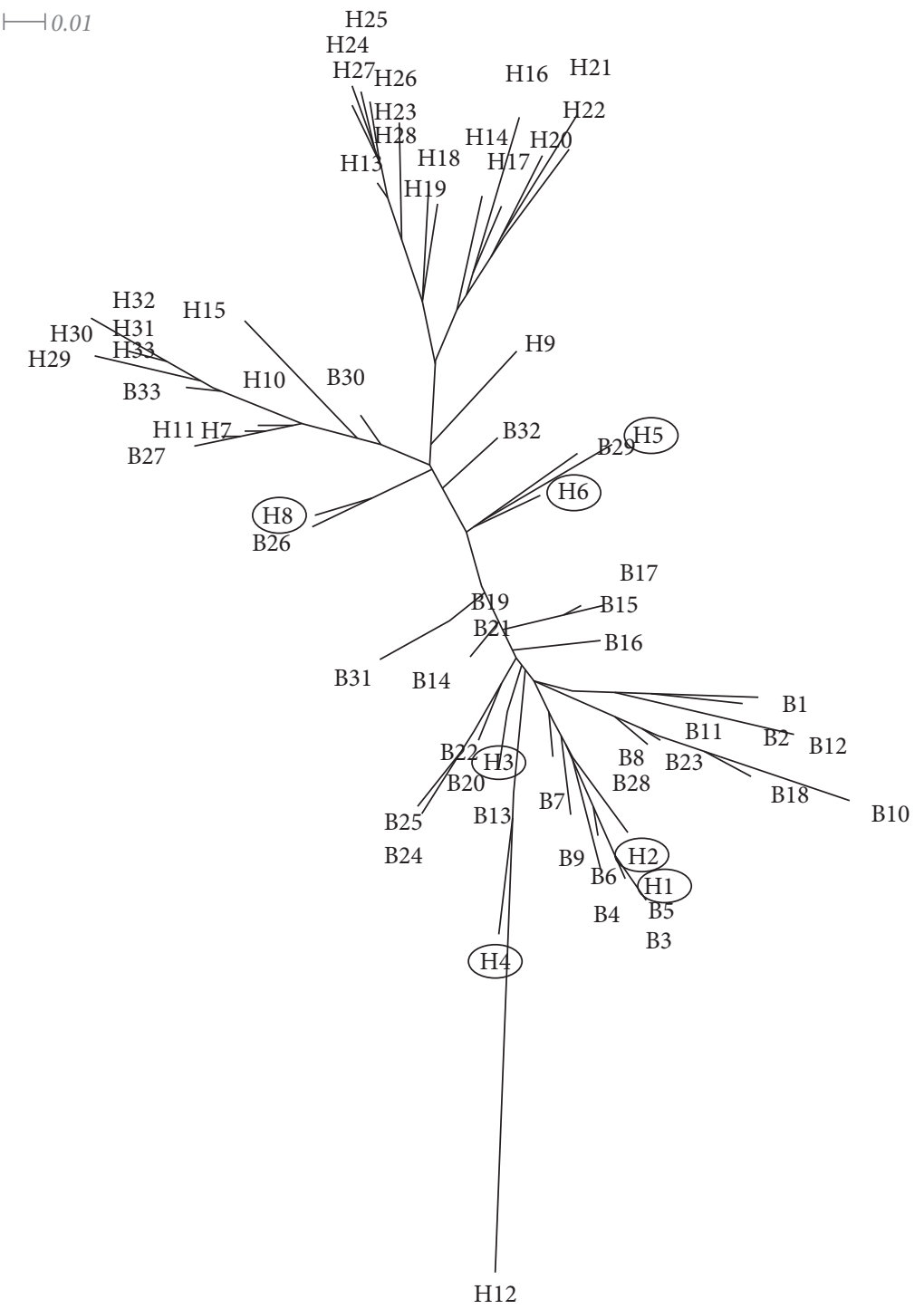

Figure 2. Unrooted Neighbour Joining Tree for 33 (B)aseline speakers and $33(\mathrm{H})$ eritage speakers.

\section{Discussion}

The discussion in this section focuses on the factors that predict which resultative construction a heritage speaker is more likely to select. 
The most important factors that have been shown in previous studies to affect proximity of a heritage speaker to the baseline revolve around the amount of use of the heritage language, which includes input (language exposure) and output (language usage) (Montrul 2008; Hammer, Komaroff, Rodriguez, Lopez, Scarpino \& Goldstein 2012). Language exposure and language usage are fundamental in promoting type and token frequency of constructions, which in turn helps the entrenchment and the automatization of constructions in the speaker's repertoire (Tomasello 2009). Theakston (2004) has shown that the frequency of use of individual verbs affects adults' judgments of sentence grammaticality, thus demonstrating that entrenchment plays a role also in adults' linguistic knowledge.

In the process of acquisition of SVCs by Dutch-Ambon Malay bilinguals, SVCs receive their degree of entrenchment only from one source (the heritage language), while PPs and APs receive their degree of entrenchment from two sources (the heritage language and the dominant language). This 'indirect' entrenchment is possible because heritage speakers establish an equivalence between the Dutch and the Ambon Malay construction. This equivalence relation allows cross-language activation. In the case of Dutch-Ambon Malay bilinguals, every time that a prepositional construction is activated in the dominant language, it automatically reinforces the corresponding construction in the heritage language. ${ }^{11}$

Evidence that 'de-serialisation' in heritage Ambon Malay is dependent on input and output related factors comes from the data gathered in the sociolinguistic interviews. I will consider two factors that have been shown to play a significant role in language contact situations, namely type of bilingualism (simultaneous vs. sequential, see Montrul 2008) and type of social network (language usage in the neighbourhood; see Hulsen, de Bot \& Weltens 2002).

The heritage speakers who are more distant from the baseline, such as $\mathrm{H} 29$, H30, H31, H32 and H33 in the NJ tree in Figure 2, never used a SVC in the video descriptions. They all grew up as simultaneous bilinguals, thus acquiring Ambon Malay and Dutch from birth. Furthermore H30 and H32 report being simply 'overhearers' during childhood because the parents spoke Dutch to them and occasionally Ambon Malay to each other. They all grew up and currently live in cities in the Randstad (industrial and metropolitan conurbation in West-central Netherlands).

The seven heritage speakers closer to the baseline (circled in Figure 2) have an individual percentage rate of SVC that is similar to that of baseline speakers. $\mathrm{H} 1, \mathrm{H} 2, \mathrm{H} 4$ and $\mathrm{H} 5$ grew up as sequential bilinguals (they started acquiring Dutch only after age 4). H1, H2, H3, H4, H5 spoke exclusively Ambon Malay with their mothers and spent their childhood in Moluccan camps. ${ }^{12} \mathrm{H} 7$ grew up speaking mostly Dutch but he married a Moluccan woman who could not speak Dutch when she arrived in the Netherlands. Finally, all but $\mathrm{H} 2$ currently live in wijken (Moluccan housing concentrations, see Veenman 1994). 
The relation between use of SVCs and language history of participants provides support for a usage-based approach to language acquisition in which the adult end-state grammar reflects the relative frequency of use of constructions in the input. Interestingly, both past and present use of the heritage language play a role in shaping the heritage grammar.

\section{Conclusion}

To conclude, heritage Ambon Malay differs significantly from the homeland variety from which it derives. Two system-preserving changes contribute to the increase in structural divergence between these two varieties: The decrease of serial verb constructions and the increase in the frequency of PPs and APs, which are becoming more entrenched and therefore more productive. I label these two contact-induced changes as 'system-preserving' because they do not involve complete loss or addition of structures in the heritage variety. At this stage, 'de-serialization' is a system-preserving change because, although resultative SVCs are avoided by some heritage speakers, other types of SVCs are still used (i.e. directional, aspectual etc.). The increase in the frequency of PPs and APs is also a system preserving change because these structures were already part of the baseline system. Although PPs and APs are rather infrequent in resultatives, they occur very often in other domains, such as in give-constructions (see Moro \& Klamer to appear; Moro \& Irizarri van Suchtelen, under review).

The cumulative effects of shifts in preference patterns, such as the one described here for resultative constructions and the one described in Muysken (2005) for possessive constructions, and in Moro \& Klamer (to appear) for double object constructions, will ultimately lead to, on the one hand, an increased dissimilarity between baseline Ambon Malay and heritage Ambon Malay and, on the other hand, an increased similarity between heritage Ambon Malay and Dutch.

The ultimate causes that account for this type of contact-induced change are sociolinguistic factors related to the language history of the speakers. Heritage speakers who became bilingual earlier and make limited use of the language (i.e. they use Dutch with partner, children and at work, and live in large cities) show a stronger entrenchment of PPs and APs, the constructions shared by Dutch. 


\section{Notes}

* I would like to thank Pieter Muysken, Suzanne Aalberse and two anonymous reviewers for their comments on an earlier version of this paper. I also thank Harald Hammarström for his invaluable help with the Neighbour Joining algorithm.

1. The baseline language is the language from which the heritage language derives. It corresponds to the language variety the heritage speaker was exposed to as a child (see Polinsky \& Kagan 2007:372).

2. Most of the Moluccans who arrived in the Netherlands spoke Tangsi Malay, a Malay variety largely based on Ambon Malay with some Javanese and Dutch elements (Adelaar \& Prentice 1996).

3. Abbreviations used: $\mathrm{ACL}=$ accidental or unintentional action, $\mathrm{DEF}=$ definite marker, $\mathrm{EXCL}=$ exclamative, $\mathrm{N}$ =neuter, $\mathrm{PERF}=$ perfective, $\mathrm{SG}=$ singular, 3 = third person.

4. In Ambon Malay there is no separate class of adjective, the property concepts of adjectives are encoded by stative verbs (van Minde 1997:66). For the sake of convenience, I adopted the term AP (Adjectival Phrase) to indicate a resultative 'stative verb phrase'.

5. This example is taken from Tjia (1997:56).

6. Only two speakers were born in Indonesia but they arrived in the Netherlands at age 1 and age 2.5 respectively.

7. The heritage Ambon Malay data and the baseline Ambon Malay data were collected by the author and by Rosina Lekawael (2011), Jusmianti Garing and Feny Eky; the Dutch data were collected by Rowan Soolsma (2013).

8. Polinsky (2008:54) has demonstrated that speech rate (words per minute output) is a good predictor of linguistic proficiency in heritage speakers.

9. The Neighbour Joining algorithm provides a principled means to derive a tree representing nested groupings from an input matrix of distances between pairs of objects, where the total distance in the tree is minimized. If the input set of objects fall into similarity groups whose mean is representative of the group, such groups should be reflected as clades in the output tree.

10. Note that B33, B32, and B30 are 82,85 and 83 years old respectively. Several studies have demonstrated that a correlation exists between aging and the reduction of syntactic complexity (Kemper \& Anagnopoulos 1989).

11. See Moro \& Irizarri van Suchtelen "Dominant language transfer in heritage languages" (under review) for a more thorough discussion of transfer effects in the domain of resultative constructions.

12. When the 12.500 Moluccans (Ambon Malay speakers) arrived in the Netherlands, they were 'temporarily' housed in 74 camps (former Nazi concentration camps). When it became clear that it was not possible for them to return to the Moluccan islands, they settled in these camps, which could host up to 2.000 inhabitants (Bartels 1986). 


\section{References}

Adelaar, K. Alexander \& David J. Prentice. 1996. Malay: Its history, role and spread. In Stephen A. Wurm, Peter Mühlhäusler \& Darrell T. Tyron (eds.), Atlas of Languages of Intercultural Communication in the Pacific, Asia, and the Americas, Vol. 1, 673-693. Berlin: Mouton de Gruyter.

Aikhenvald, Alexandra Y. 2006. Serial verb constructions in typological perspective. In Alexandra Y. Aikhenvald \& Robert M. Dixon (eds.), Serial Verb Constructions: A Crosslinguistic Typology, 1-68. Oxford: Oxford University Press.

Backus, Ad. 2004. Convergence as a mechanism of language change. Bilingualism: Language and Cognition 7(2). 179-181. DOI: 10.1017/S1366728904001567

Bartels, Dieter. 1986. Can the train ever be stopped again? Developments in the Moluccan community in the Netherlands before and after the hijackings. Indonesia 41. 23-45.

DOI: $10.2307 / 3351034$

Boas, Hans. 2003. A constructional approach to resultatives. Stanford: CSLI.

Bohnemeyer, Jürgen, Melissa Bowerman \& Penelope Brown. 2001. Cut and break clips. In Stephen C. Levinson \& Nick Enfield (eds.), Manual for the Field Season 2001, 90-96. Nijmegen: Max Planck Institute for Psycholinguistics.

Boumans, Louis. 2006. The attributive possessive in Moroccan Arabic spoken by young bilinguals in the Netherlands and their peers in Morocco. Bilingualism: Language and Cognition 9(3). 213-231. DOI: 10.1017/S1366728906002598

Croft, William, Jóhanna Barðdal, Willem Hollmann, Violeta Sotirova \& Chiaki Taoka. 2010. Revising Talmy's typological classification of complex event constructions. In Hans C. Boas (ed.), Contrastive Studies in Construction Grammar, 201-235. Amsterdam/Philadelphia: John Benjamins. DOI: 10.1075/cal.10.09cro

Elektronische Algemene Nederlandse Spraakkunst (E-ANS). 1997. Version 1.3. Available at http:// ans.ruhosting.nl/e-ans/index.html (30 June, 2014).

Ellis, Nick. C. 2006. Language acquisition as rational contingency learning. Applied Linguistics 27(1). 1-24. DOI: 10.1093/applin/ami038

Goldberg, Adele. 1995. Constructions: A construction grammar approach to argument structure. Chicago: University of Chicago Press.

Hajek, John. 2006. Serial verbs in Tetun Dili. In Alexandra Y. Aikhenvald \& Robert M. Dixon (eds.), Serial Verb Constructions: A Cross-linguistic Typology, 239-253. Oxford: Oxford University Press.

Hammer, Scheffner Carol, Eugene Komaroff, Barbara L. Rodriguez, Lisa M. Lopez, Shelley E. Scarpino \& Brian Goldstein. 2012. Predicting Spanish-English Bilingual Children's Language Abilities. Journal of Speech, Language, and Hearing Research 55. 1251-1264. DOI: 10.1044/1092-4388(2012/11-0016)

Hulsen, Madeleine, Kees de Bot \& Bert Weltens. 2002. "Between two worlds." Social networks, language shift, and language processing in three generations of Dutch migrants in New Zealand. International Journal of the Sociology of Language 153. 27-52.

Huwaë, Rosita. 1992. Tweetaligheid in Wierden: het taalgebruik van jongeren uit een Molukse gemeenschap. Amsterdam: University of Amsterdam dissertation.

Jansen, Bert, Josien Lalleman \& Pieter Muysken. 1981. The alternation hypothesis: acquisition of Dutch word order by Turkish and Moroccan foreign workers. Language Learning 31(2). 315-336. DOI: 10.1111/j.1467-1770.1981.tb01387.x 
Johanson, Lars. 2002. Contact-induced change in a code-copying framework. In Mari C. Jones \& Edith Esch (eds.), Language Change: The Interplay of Internal, External and Extra-linguistic Factors, 285-314. Berlin: Mouton de Gruyter.

Kaufmann, Ingrid \& Dieter Wunderlich. 1998. Cross-linguistic patterns of resultatives. Manuscript. Heinrich-Heine Universität, Düsseldorf.

Van Kemenade, Ans \& Bettelou Los. 2003. Particles and prefixes in Dutch and English. In Geert Booij \& Jaap van Marle (eds.), Yearbook of Morphology, 79-117. New York: Kluwer Academic. DOI: 10.1007/978-1-4020-1513-7_5

Kemper, Susan \& Cheryl Anagnopoulos. 1989. Language and aging. Annual Review of Applied Linguistics 10. 37-50. DOI: 10.1017/S0267190500001203

Lekawael, Rosina. 2011. The development of Moluccan Malay as a heritage language in the Netherlands. Nijmegen: Radboud University MA thesis.

Levin, Beth. 1993. English verb classes and alternations: A preliminary investigation. Chicago: University of Chicago press.

Van Minde, Don. 1997. Malayu Ambong. Leiden: Research School CNWS.

Montrul, Silvina. 2008. Incomplete acquisition in bilingualism. Re-examining the age factor. Amsterdam: John Benjamins. DOI: 10.1075/sibil.39

Moro, Francesca R. \& Marian Klamer. To appear. Give-constructions in heritage Ambon Malay in the Netherlands. Journal of Language Contact.

Moro, Francesca R. \& Pablo Irizarri van Suchtelen. Under review. Dominant language transfer in heritage languages. Manuscript.

Muysken, Pieter. 2005. Possessive constructions in language contact settings. Monash University Linguistics Papers 4(1). 11-19.

Muysken, Pieter. 2013. Language contact outcomes as the result of bilingual optimization strategies. Bilingualism: Language and Cognition 16(4). 709-730.

DOI: $10.1017 /$ S1366728912000727

O’Grady, William, Hye-Young Kwak, On-Soon Lee \& Miseon Lee. 2011. An emergentist perspective on heritage language acquisition. Studies in Second Language Acquisition 33(2). 223-245. DOI: 10.1017/S0272263110000744

Onar Valk, Pelin \& Ad Backus. 2013. Syntactic change in an immigrant language: From non-finite to finite subordinate clauses in Turkish. Eesti ja soome-ugri keeleteaduse ajakiri. Journal of Estonian and Finno-Ugric Linguistics 4(2). 7-29.

Polinsky, Maria. 2008. Gender under incomplete acquisition. Heritage Language Journal 6(1). 40-71.

Polinsky, Maria \& Olga Kagan. 2007. Heritage languages: In the 'wild'and in the classroom. Language and Linguistics Compass 1(5). 368-395.

Saitou, Naruya \& Masatoshi Nei. 1987. The neighbor-joining method: A new method for reconstructing phylogenetic trees. Molecular Biology and Evolution 4(4). 406-425.

Silva-Corvalán, Carmen. 1994. Language Contact and Change: Spanish in Los Angeles. Language Variation and Change. Oxford: Clarendon Press.

Silva-Corvalán, Carmen. 2008. The limits of convergence in language contact. Journal of Language Contact 2(1). 13-224. DOI: 10.1163/000000008792525246

Soolsma, Rowan. 2013. De progressief in het Nederlands en het Moluks Maleis. Nijmegen: Radboud University MA thesis.

Tahitu, Bert. 1989. Melaju Sini. Het Maleis van Molukse jongeren in Nederland. Leiden: Leiden University dissertation. 
Talmy, Leonard. 2000. Toward a cognitive semantics: Typology and process in concept structuring. Cambridge, MA: MIT Press.

Theakston, Anna L. 2004. The role of entrenchment in children's and adults' performance on grammaticality judgment tasks. Cognitive Development 19(1). 15-34.

DOI: 10.1016/j.cogdev.2003.08.001

Tjia, Johnny. 1997. Verb serialization in Ambonese Malay. Eugene, OR: University of Oregon MA thesis.

Tomasello, Michael. 2009. Constructing a language: A usage-based theory of language acquisition. Harvard: Harvard University Press.

Tomasello, Michael. 2000. First steps toward a usage-based theory of language acquisition. Cognitive Linguistics 11(1). 61-82.

Veenman, Justus. 1994. The social integration of Moluccans. Rotterdam: Koninklijke Vermande/ ISEO.

\section{Author's address}

Francesca Moro

Centre for Language Studies

Department of Linguistics

Radboud University Nijmegen

Erasmusplein 1

6525 HT Nijmegen, The Netherlands

f.moro@let.ru.nl 